\title{
Modeling the Benefits of Storage Technologies to Wind Power
}

Conference Paper NREL/CP-670-43510 June 2008

Patrick Sullivan, Walter Short, and Nate Blair

Presented at the American Wind Energy Association (AWEA) WindPower 2008 Conference

Houston, Texas

June 1-4, 2008 


\section{NOTICE}

The submitted manuscript has been offered by an employee of the Midwest Research Institute (MRI), a contractor of the US Government under Contract No. DE-AC36-99G010337. Accordingly, the US Government and MRI retain a nonexclusive royalty-free license to publish or reproduce the published form of this contribution, or allow others to do so, for US Government purposes.

This report was prepared as an account of work sponsored by an agency of the United States government. Neither the United States government nor any agency thereof, nor any of their employees, makes any warranty, express or implied, or assumes any legal liability or responsibility for the accuracy, completeness, or usefulness of any information, apparatus, product, or process disclosed, or represents that its use would not infringe privately owned rights. Reference herein to any specific commercial product, process, or service by trade name, trademark, manufacturer, or otherwise does not necessarily constitute or imply its endorsement, recommendation, or favoring by the United States government or any agency thereof. The views and opinions of authors expressed herein do not necessarily state or reflect those of the United States government or any agency thereof.

Available electronically at http://www.osti.gov/bridge

Available for a processing fee to U.S. Department of Energy and its contractors, in paper, from:

U.S. Department of Energy

Office of Scientific and Technical Information

P.O. Box 62

Oak Ridge, TN 37831-0062

phone: 865.576 .8401

fax: 865.576 .5728

email: mailto:reports@adonis.osti.gov

Available for sale to the public, in paper, from:

U.S. Department of Commerce

National Technical Information Service

5285 Port Royal Road

Springfield, VA 22161

phone: 800.553 .6847

fax: 703.605.6900

email: orders@ntis.fedworld.gov

online ordering: http://www.ntis.gov/ordering.htm 


\title{
Modeling the Benefits of Storage Technologies to Wind Power
}

\author{
Patrick Sullivan, Walter Short, Nate Blair \\ National Renewable Energy Laboratory ${ }^{1}$ \\ 1617 Cole Boulevard \\ Golden, CO 80401 \\ patrick_sullivan@nrel.gov \\ June, 2008
}

\section{Introduction}

Rapid expansion of wind power in the electricity sector is raising questions about how wind resource variability might affect the capacity value of wind farms at high levels of penetration. Electricity storage, with the capability to shift wind energy from periods of low demand to peak times and to smooth fluctuations in output, may have a role in bolstering the value of wind power at levels of penetration envisioned by a new Department of Energy report, “20\% Wind by 2030, Increasing Wind Energy's Contribution to U.S. Electricity Supply"2 released in May, 2008.

Utilities are still experimenting to determine the capacity value - the amount of conventional capacity a given amount of wind capacity can replace - of the wind farms they are building today. No matter how accurate forecasting of wind patterns becomes, the nature of the resource does not allow operators to dispatch wind power to meet load as they can with a conventional plant. Storage technologies provide synergies with wind power either by shifting electricity from periods of low demand to those of higher demand, or by damping out fluctuations in output. This process helps reduce stresses on other plants that would otherwise have to ramp up and down to compensate for the variations from the wind farms. The more wind installed in a system, the more valuable storage becomes - at higher penetrations, wind variations are larger and there is less balance-of-system to compensate.

This paper quantifies the value storage can add to wind. The analysis was done employing the Regional Energy Deployment System (ReEDS) model, formerly known as the Wind Deployment System (WinDS) model (http://www.nrel.gov/analysis/winds/). ReEDS, developed at the National Renewable Energy Laboratory (NREL), was used to estimate the cost and development path associated with $20 \%$ penetration of wind in the " $20 \%$ Wind by 2030 " report. ReEDS differs from the WinDS model primarily in that the model has been modified to include the capability to build and use three storage technologies: pumped-hydroelectric storage (PHS), compressed-air energy storage (CAES), and batteries

To assess the value of these storage technologies, two pairs of scenarios were run:

- business-as-usual, with and without storage

- $20 \%$ wind energy by 2030 , with and without storage

This paper presents the results from those model runs.

\footnotetext{
${ }^{1}$ NREL is a national laboratory of the U.S. Department of Energy, Office of Energy Efficiency and Renewable Energy, operated by Midwest Research Institute and Battelle

${ }^{2}$ DOE EERE “20 \% Wind by 2030, Increasing Wind Energy's Contribution to U.S. Electricity Supply”, DOE/GO102008-2567, May 2008.
} 


\section{ReEDS Overview}

The ReEDS model began in $2003^{3}$ to examine the expansion of generation and transmission capacity in the U.S. electric sector. ReEDS is a linear programming model that minimizes system-wide costs of meeting loads, reserve requirements, and emission constraints by building and operating power generators and transmission capacity in each of 23 two-year periods spanning 2006-2050. Although ReEDS considers all major generator types, it was designed primarily to address the principal market issues related to the penetration of wind energy into the electric sector over the next several decades - specifically, wind resource variability and transmission requirements.

ReEDS is better able to model transmission and wind resource variability, primarily by using a much higher level of geographic disaggregation than other models-358 distinct regions in the continental United States, illustrated in Figure 1. Many of the data inputs to ReEDS are tied to these regions and derived from a detailed geographic information system (GIS) model/database of the wind resource, transmission grid, and existing plant data. The geographic disaggregation of wind resource allows ReEDS to calculate transmission distances (and charge appropriately) as well as account for regional differences in wind resource.

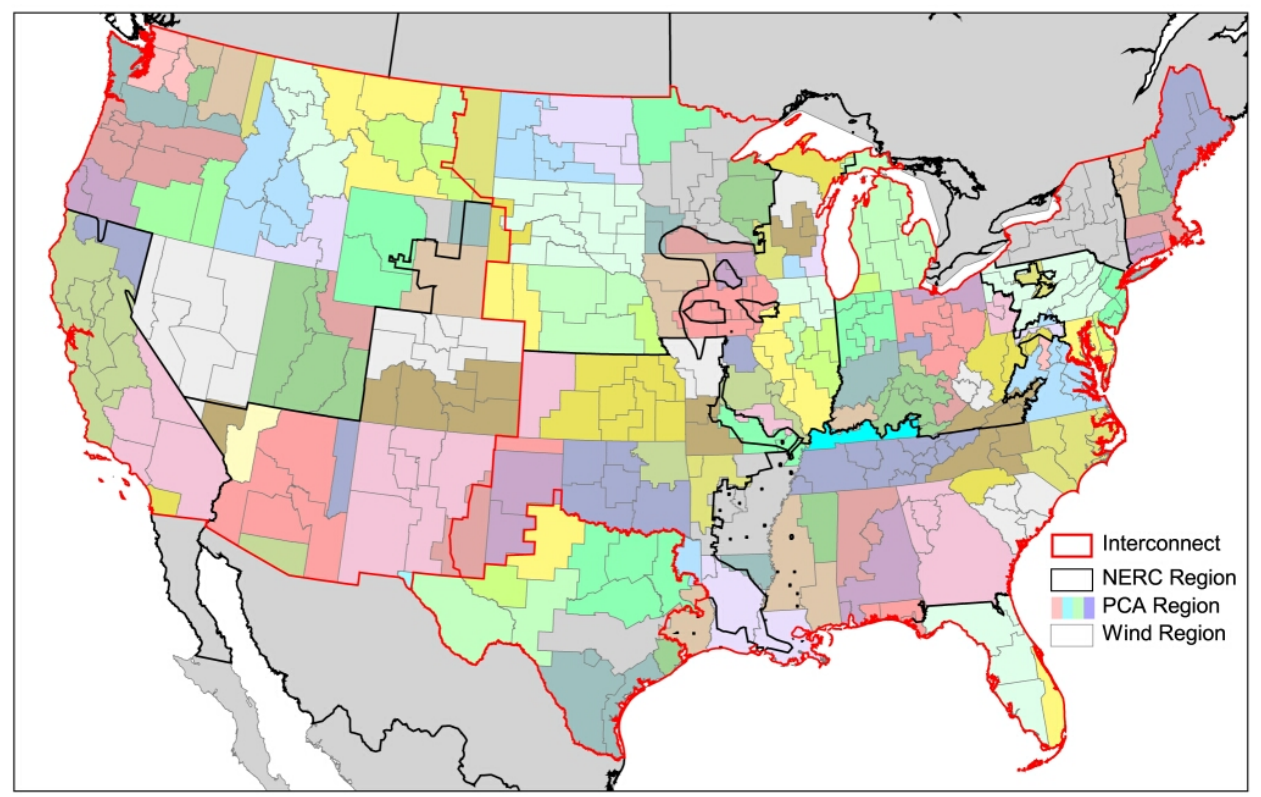

Figure 1. ReEDS regions

ReEDS considers the availability of capacity on existing transmission lines, the cost of accessing and using those lines, and the cost of building new transmission lines dedicated to wind generation when existing lines are not available. These costs are made to reflect current electricity transmission pricing as realistically as possible.

\footnotetext{
${ }^{3}$ Short, Walter; et al., May 2003, "Modeling the Long-Term Penetration of Wind in the United States," WindPower 2003 Proceedings, Austin, Texas
} 
ReEDS disaggregates the wind resource into five classes ranging from Class 3 (5.4 meters/second at 10 meters above ground) to Class $7(>7.0 \mathrm{~m} / \mathrm{s})$ for the lower 48 states (see Figure 2). Each class and each region has a unique diurnal generation profile so in those parts of the country where the wind generally blows more strongly at night than during the day, for instance, the model reflects that and takes it into account when stochastically determining the capacity value. The stochastic calculations also include wind already supplying the grid and apply statistical measures to account for the fact that wind farms that are closer together are more likely to have their output profiles correlated than wind farms that are widely separated. The more correlated the outputs, the lower the capacity value.

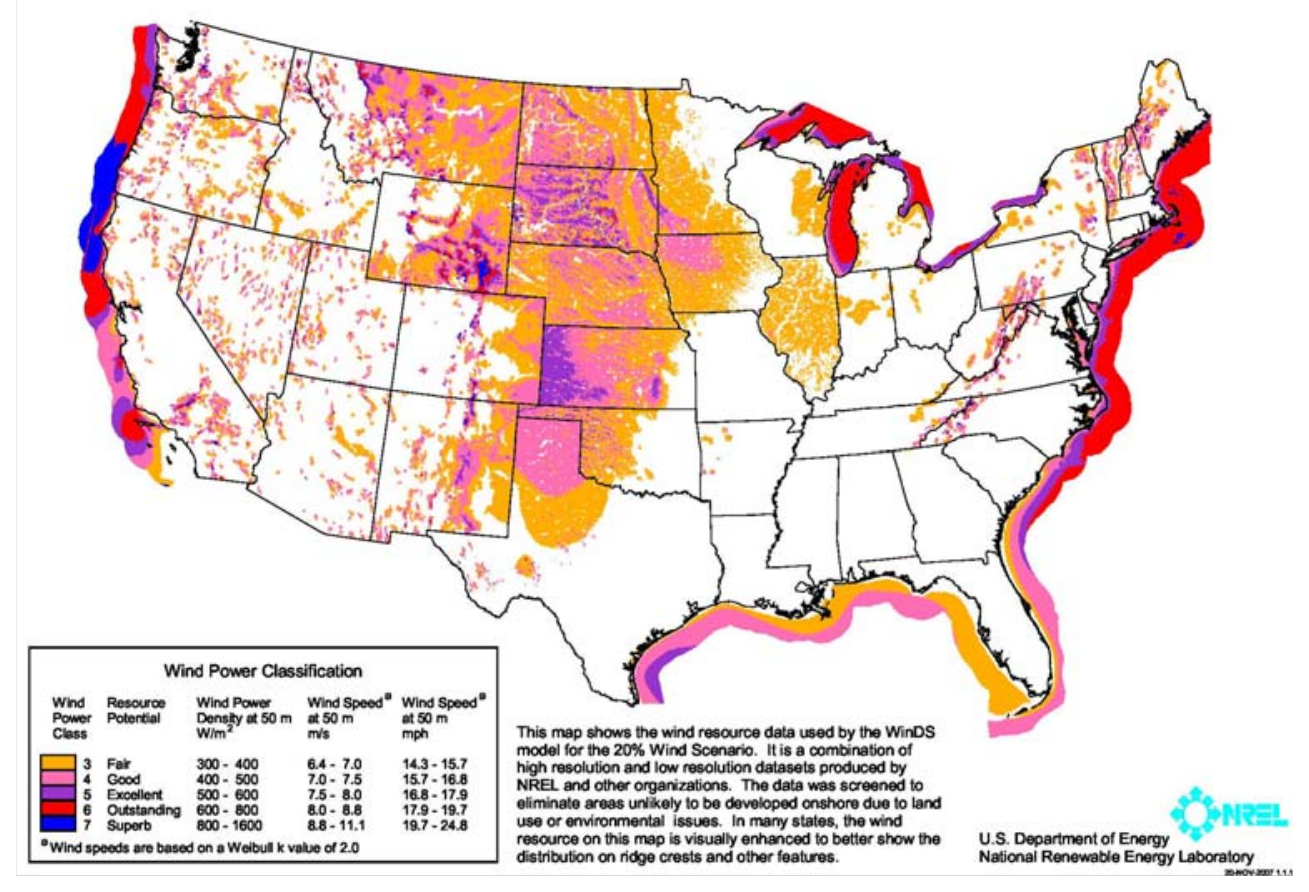

Figure 2. Wind resources in ReEDS

Each class of wind has different cost and performance characteristics. Often, higher wind-class sites are more desirable, though additional expenses for transmission, terrain, and population considerations can make, for example, an otherwise high-quality, but remote, Class-7 resource much more expensive than a more conveniently located Class-5 site. The result is that a mix of classes is built in a given year - a mix that changes over time - depending on which class is the cheapest in that particular region at that time.

ReEDS is also disaggregated over time, not only with the two-year periods, but also within each year. ReEDS has 16 time-slices: four seasons, each with four daily slices (except spring, which has three); and one super-peak slice to account for the few highest-demand hours in the summer. These 16 time-slices allow ReEDS to capture the intricacies of meeting peak electric loads with both conventional sources and intermittent wind generators. 
ReEDS models the major conventional electricity generators, including:

- pulverized coal: traditional and next generation

- integrated gasification combined-cycle coal (IGCC)

- natural gas combined cycle

- natural gas combustion turbines

- nuclear

- hydroelectricity: existing only, and energy limited by water-use requirements

Fuel costs are specified exogenously by time and by North American Electric Reliability Corporation (NERC) region, as are the electric loads. In addition, ReEDS has the capability to consider a renewable portfolio standard (RPS) -a requirement that a certain percentage or quantity of capacity or generation be derived from renewables - at state and national levels; meet emission caps for $\mathrm{SO}_{2}, \mathrm{NO}_{\mathrm{x}}$, mercury, and $\mathrm{CO}_{2}$; impose a carbon tax; and adjust options for financing of capital expenditures and tax credits for investment or production.

\section{Storage in ReEDS}

Storage can provide benefit to the system in three ways, each loosely associated with a timescale. On super-hourly timescales, storage can provide load-shifting and arbitrage usually by charging overnight and discharging during peak afternoon or evening hours. Load-shifting is by no means of exclusive utility to wind power: a fully conventional system can benefit from the practice by running cheaper plants at a slightly higher level overnight to bank energy and then call on that storage during the day instead of dispatching an expensive peaking plant. On the other hand, because wind tends to blow harder at night in many parts of the country, the benefit can be even greater for wind-heavy systems.

On shorter timescales, storage can be used to smooth variations in wind farm output, reducing the need for conventional spinning reserve to be ready to either take up slack or back off to adjust to changes in wind. A wind-heavy system without storage would need substantial amounts of responsive capacity to be able to rapidly ramp up or down; this means that such capacity must be both built and operated, at substantial cost to the system. A quick-ramping storage technology with enough stored energy for a few hours of output might be a better option than a gas turbine in certain circumstances.

Quick-acting storage can also add value by providing voltage and frequency regulation and other similar ancillary services.

As implemented in ReEDS, storage can provide some of these benefits explicitly and others implicitly. Storage can charge or discharge in any of 16 time slices, directly allowing for load shifting between periods of low demand and high demand. Additionally, any capacity unused for either charging or discharging in a given period is available as operating reserve, allowing storage to address wind smoothing and ancillary services. Of course, storage also counts toward available capacity as well, for meeting peak load and reserve margin requirements. 
In ReEDS, three types of storage are permitted: pumped hydro storage (PHS), compressed air energy storage (CAES), and batteries. The battery chemistry assumed in the model - chosen on the basis of the current robustness of the technology and well-established and competitive costs - is sodium-sulfur. Cost/performance parameters for the storage technologies are listed in Table 1. Costs for each technology are for systems with eight hours of storage.

Table 1. Storage Technology Cost and Performance Data (\$2004)

\begin{tabular}{|c|c|c|c|c|c|c|}
\hline & & $\begin{array}{l}\text { Capital Cost } \\
1000 \$ / \mathrm{MW}\end{array}$ & $\begin{array}{l}\text { Fixed O\&M } \\
\text { \$/MW-year }\end{array}$ & $\begin{array}{l}\text { Variable } \\
\text { O\&M } \\
\text { \$/Mwh }\end{array}$ & $\begin{array}{l}\text { Round Trip } \\
\text { Efficiency }\end{array}$ & $\begin{array}{l}\text { Heat Rate } \\
\text { Mbtu/MWh }\end{array}$ \\
\hline \multirow[t]{3}{*}{ PHS } & 2010 & 1500 & 12720 & 5.0 & 0.80 & \\
\hline & 2020 & 1500 & 12720 & 5.0 & 0.80 & \\
\hline & 2030 & 1500 & 12720 & 5.0 & 0.80 & \\
\hline \multirow[t]{3}{*}{ Battery $^{4}$} & 2010 & 1964 & 51000 & 5.0 & 0.77 & \\
\hline & 2020 & 1810 & 47002 & 5.0 & 0.78 & \\
\hline & 2030 & 1668 & 43317 & 5.0 & 0.80 & \\
\hline \multirow[t]{3}{*}{$\mathrm{CAES}^{5}$} & 2010 & 840 & 10310 & 3.1 & 1.38 & 4.40 \\
\hline & 2020 & 820 & 10105 & 3.1 & 1.40 & 4.30 \\
\hline & 2030 & 820 & 10105 & 3.1 & 1.40 & 4.30 \\
\hline
\end{tabular}

CAES is not a pure storage technology; for the storage portion, cheap electricity is used to charge the reservoir, in this case by pumping high-pressure air into an underground cavern (e.g., a salt dome). Upon discharging, however, the compressed air is mixed with natural gas and combusted before expanding it through a turbine to generate power. In effect, CAES is a hybrid technology that uses electrical-to-physical storage to enable a highly efficient combustion turbine; the heat rate of a CAES plant is roughly half that of a traditional natural gas plant. Because there are two inputs (electricity and natural gas), it is difficult to create a single performance metric, so the table above includes both round-trip efficiency and heat rate. For every $0.72 \mathrm{MWh}$ of electricity and $4.4 \mathrm{Mbtu}$ of gas, the plant will provide $1 \mathrm{MWh}$ of electricity.

ReEDS can choose to build storage either co-located with wind farms or sited at the load. In either case, the storage can be charged in ReEDS by either wind generated electricity or generation from the general grid (see Figure 3). The primary advantage of co-locating with wind is the potential to save money by downsizing a long transmission line. (With a $100 \mathrm{MW}$ wind farm, a $20 \mathrm{MW}$ battery allows the developer to build a transmission line of only $80 \mathrm{MW}$ without risking losing energy generated by the top $20 \mathrm{MW}$.) There is a trade-off in that the maximum capacity the combined wind-storage system can generate is then limited by the transmission line. Storage at the load does not allow downsized transmission, but the storage will always be able to discharge at full power. Storage at load also assists the movement of wind power to load centers by charging overnight when transmission lines are relatively free, rather than trying to move the power during peak hours when the lines are congested. Storage at the load also allows slightly more wind energy to be stored for the same storage capacity since transmission losses are incurred before the load-sited storage. Similarly, storage at the load site charged from the general grid does not incur transmission losses to and from a remote wind-sited storage facility.

\footnotetext{
${ }^{4}$ Electric Power Research Institute (EPRI)/Department of Energy (DOE). "EPRI-DOE Handbook of Energy Storage for Transmission and Distribution Applications." 2003.

${ }^{5}$ Holst, Kent. "Iowa Stored Energy Plant: Status Report," California Energy Commission. February 2005.
} 


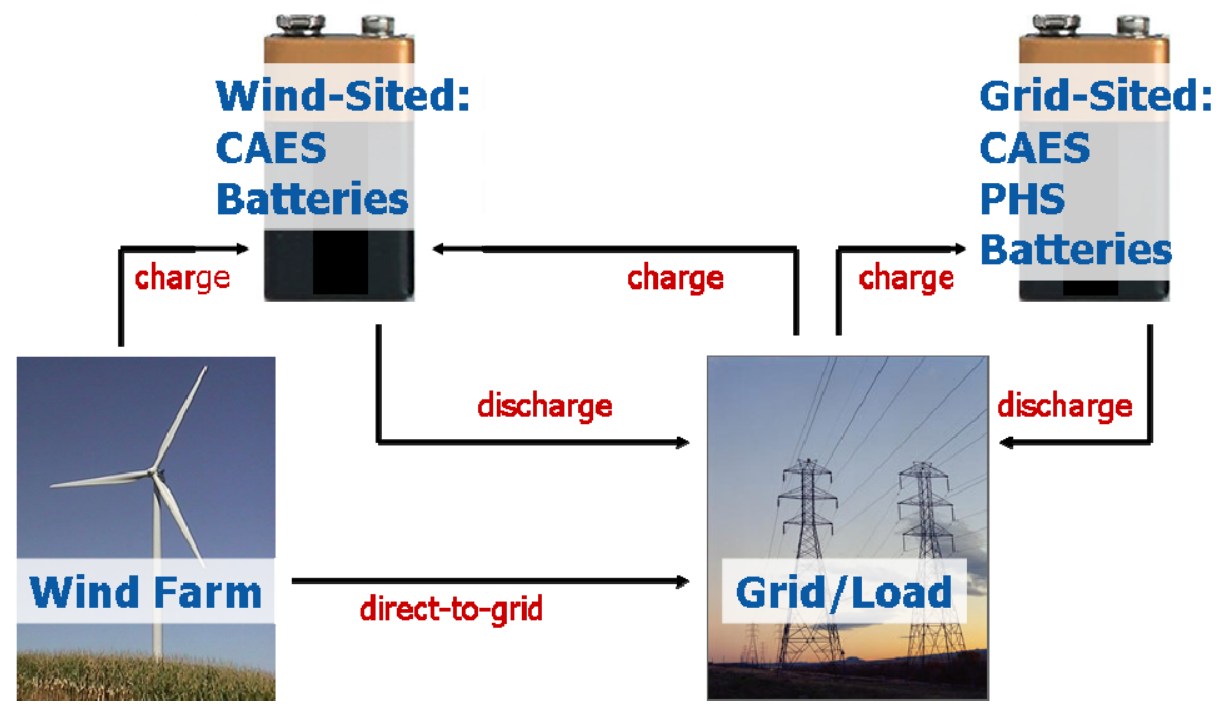

Figure 3. Storage-wind-grid interconnections

There are $21 \mathrm{GW}$ of utility-scale electric storage currently in use in the United States, the vast bulk of which is PHS. A single $110 \mathrm{MW}$ CAES plant operates in McIntosh, Alabama. For further expansion, the model restricts PHS to load-located only, assuming that the odds of finding appropriate hydrological features at many attractive wind sites are slim. Because much of the country has geological features appropriate to CAES caverns (e.g., aquifers, domal salt, or bedded salt), wind-located CAES is permitted. However, CAES of either type is restricted in regions without appropriate geology (Figure 4 shows where suitable geology exists). Batteries can be installed anywhere.

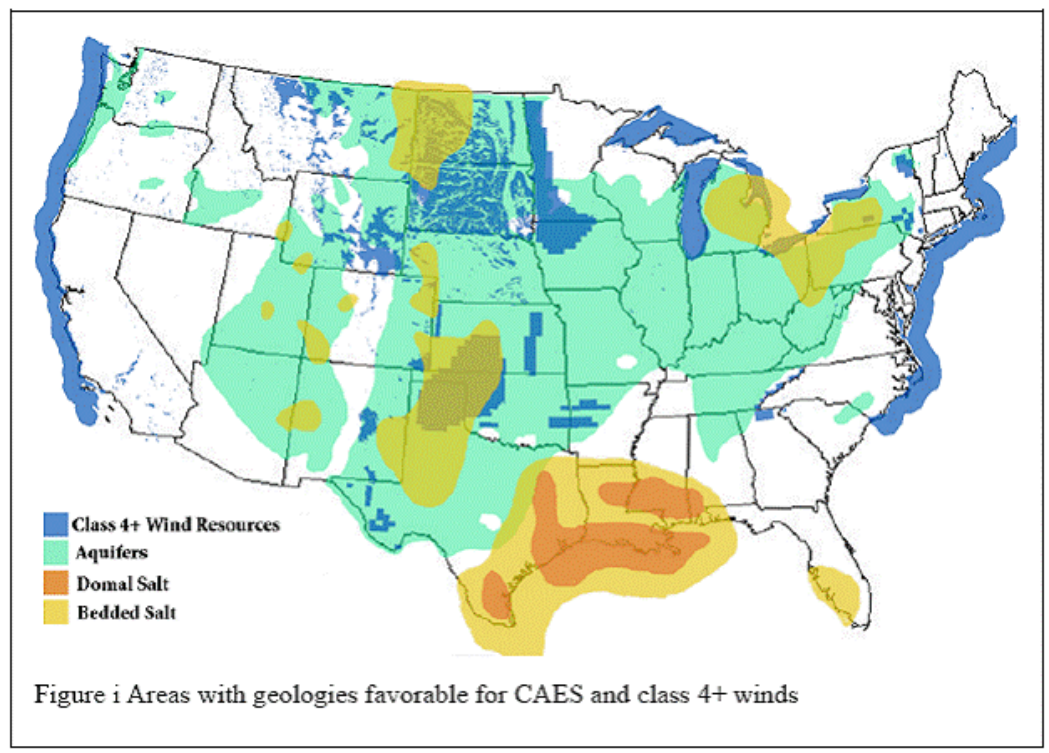

Figure 4. Potential CAES locations ${ }^{6}$

\footnotetext{
${ }^{6}$ Succar, S. and R. Williams. “Compressed Air Energy Storage: Theory, Operation, and Applications.” March 2008.
} 


\section{Business-As-Usual Scenarios}

The business-as-usual scenario for this comparison trial uses values from the Reference Case of the Annual Energy Outlook (AEO) $2006^{7}$ for input data for fuel prices and load forecasts. Wind data inputs and costs for conventional technologies are from Black \& Veatch and match those used in the "20\% Wind by 2030 " report. Tables 2 and 3 contain the technology cost and performance data used in this analysis. Other inputs are set according to current conditions: no national renewable portfolio standard (RPS), but state standards are enforced if currently enacted; the $\mathrm{SO}_{2}$ cap follows current regulations; no carbon cap or tax is applied.

Table 2. Onshore Wind Cost and Performance Data (2004\$)

\begin{tabular}{ll|llll} 
Class & Year & $\begin{array}{l}\text { Capital Cost } \\
\text { k\$MW }\end{array}$ & $\begin{array}{l}\text { Fixed O\&M } \\
\text { \$/MW-year }\end{array}$ & $\begin{array}{l}\text { Variable O\&M } \\
\text { \$MW }\end{array}$ & Capacity Factor \\
\hline 3 & 2010 & 1570 & 10946 & 5.19 & 0.35 \\
& 2020 & 1490 & 10946 & 4.41 & 0.38 \\
\hline 4 & 2030 & 1413 & 10946 & 4.16 & 0.38 \\
\hline 5 & 2010 & 1570 & 10946 & 5.19 & 0.39 \\
& 2020 & 1490 & 10946 & 4.41 & 0.42 \\
& 2030 & 1413 & 10946 & 4.16 & 0.43 \\
\hline 6 & 2010 & 1570 & 10946 & 5.19 & 0.43 \\
& 2020 & 1490 & 10946 & 4.41 & 0.45 \\
& 2030 & 1413 & 10946 & 4.16 & 0.46 \\
\hline 7 & 2010 & 1570 & 10946 & 5.19 & 0.46 \\
& 2020 & 1490 & 10946 & 4.41 & 0.48 \\
& 2030 & 1413 & 10946 & 4.16 & 0.49 \\
\hline 2010 & 1570 & 10946 & 5.19 & 0.50 \\
& 2020 & 1490 & 10946 & 4.41 & 0.52 \\
& 2030 & 1413 & 10946 & 4.16 & 0.53
\end{tabular}

Table 3. Selected Conventional Cost and Performance Data (2004 \$)

\begin{tabular}{ll|llll} 
Technology & Year & $\begin{array}{l}\text { Capital Cost } \\
\text { k\$MW }\end{array}$ & $\begin{array}{l}\text { Fixed O\&M } \\
\text { \$MW-year }\end{array}$ & $\begin{array}{l}\text { Variable O\&M } \\
\text { \$MWh }\end{array}$ & Heat Rate \\
\hline Natural Gas & 2010 & 714 & 6281 & 2.67 & 8.90 \\
Combustion Turbine & 2020 & 714 & 6281 & 2.67 & 8.90 \\
& 2030 & 714 & 6281 & 2.67 & 8.90 \\
\hline Natural Gas & 2010 & 742 & 13706 & 2.86 & 6.87 \\
Combined Cycle & 2020 & 742 & 13706 & 2.86 & 6.87 \\
\hline New & 2030 & 742 & 13706 & 2.86 & 6.87 \\
Pulverized Coal & 2010 & 2075 & 33600 & 1.62 & 9.47 \\
& 2020 & 2132 & 33600 & 1.62 & 9.47 \\
\hline Coal IGCC & 2030 & 2132 & 33600 & 1.62 & 9.47 \\
\hline Nuclear & 2010 & 2703 & 36264 & 3.71 & 8.58 \\
& 2020 & 2703 & 36264 & 3.71 & 8.58 \\
& 2030 & 2703 & 36264 & 3.71 & 8.58 \\
\hline
\end{tabular}

\footnotetext{
${ }^{7}$ U.S. Department of Energy, Energy Information Administration. Annual Energy Outlook 2006 with Projections to 2030. DOE/EIA-0383, February 2006.

${ }^{8}$ Personal communication with Ric O’Connell, Black \& Veatch. January, 2007.
} 




Figure 5. Cumulative installed capacity, business-as-usual with-storage case

Figure 5 shows the cumulative installed capacity for the business-as-usual case with storage. The two business-as-usual cases are identical except that the model has the option of building and using storage only in the second. (The first does not even have access to the existing $21 \mathrm{GW}$, a decision that was made because the goal of the study was to examine the value of storage in general rather than the value of additional storage.) Therefore, comparisons between the two can rely on having similar economics driving the decisions. The most substantial difference in the results is that an additional $50 \mathrm{GW}$ of wind power are installed in the storage case (Figure 6). Figure 7 shows the delta between the two cases for both storage additions and wind. Until about 2042, storage and wind both grow; while after 2042 storage grows in support of nuclear, not wind.

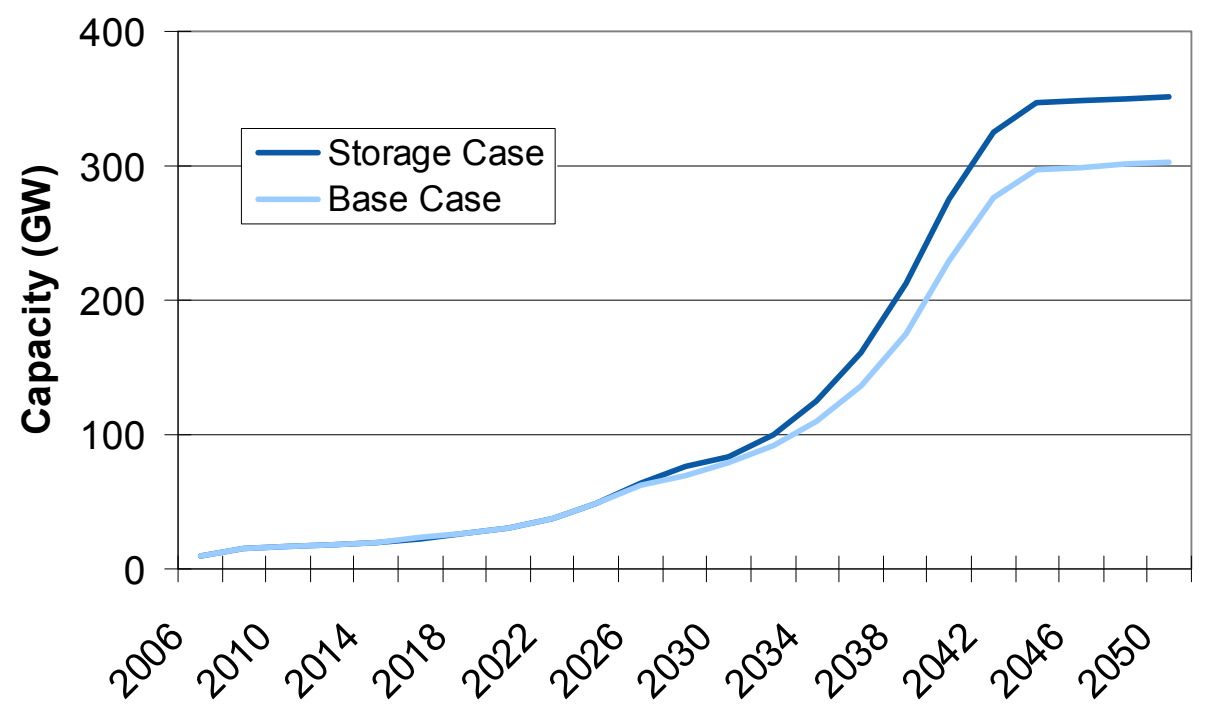

Figure 6. Cumulative wind capacity comparison, business-as-usual cases 


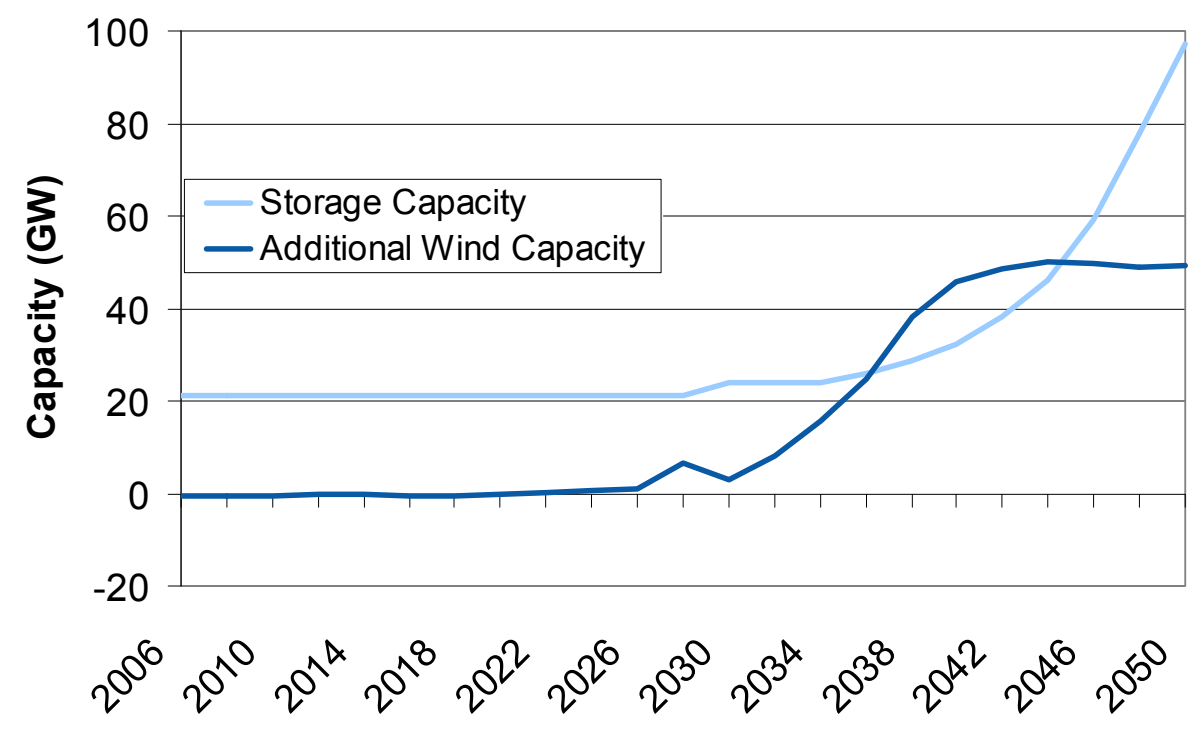

Figure 7. Effect of storage on wind capacity, business-as-usual cases

The storage and additional wind in the storage case contribute to energy and capacity requirements and reduce the need for conventional plants. Figure 8 shows comparisons of capacity and generation between the two scenarios. Coal, gas, and nuclear capacity are all lower in 2050 in the storage case ("coal-old" is coal capacity that already exists in 2006, so its capacity is essentially the same in both cases), having been replaced by wind and storage. Energy-wise, coal, gas, and nuclear generation are again all down, though "coal-old" has a net increase. It makes sense for an existing cheap base-load technology to increase generation when storage is available because excess overnight generation can now be stored and dispatched during the day to replace electricity from expensive gas plants. 



Figure 8. 2050 capacity and generation comparison, business-as-usual cases

It should be noted that all storage built in all four scenarios (except for the existing PHS) is CAES and is located with the load. Regarding the former, CAES plants have substantially lower capital and operating costs than either PHS or batteries, and the fuel costs are relatively low. CAES is widely considered to be the cheapest of the utility-scale storage options today, and these results support that. It is certainly possible that battery technology could improve enough before 2050 to become competitive with CAES; however, with the projections used in this study, that did not occur. A less-expensive battery option probably would not substantially change the results, and what changes there were would serve to reinforce the benefits of storage. As for the lack of wind-located storage; the capacity, transmission loss, and congestion penalties evidently outweighed the cost savings of downsizing transmission lines.

\section{$520 \%$ Wind by 2030 Scenarios}

In the $20 \%$ wind by 2030 scenarios, the model is required to ramp up to generating $20 \%$ of annual energy from wind by 2030 and to maintain that level thereafter. Both cases (with and without storage), therefore, build similar amounts of wind (for this analysis, non-wind renewables, such as solar, biopower, and geothermal, were not included). Figure 9 shows cumulative capacity for the with-storage case.

One metric that can be used to compare the scenarios is the price of electricity, which is lower in the storage case by more than $\$ 2 / \mathrm{MWh}$ by 2050 , the delta having increased steadily since the mid-2020s (see Figure 10). The price difference can be partially attributed to a 
reduction in the amount of conventional capacity built (more combustion turbines are necessary in the no-storage case to back up the wind), and in the amount of generation from those plants. The other factor is that, with the ability to store off-peak wind, some wind farms that may have been cheap yet undeveloped without storage - perhaps due to an unfavorable diurnal profile or high wind variance - may become highly desirable when storage is available. Those sites can then be built out economically, replacing other more expensive sites.

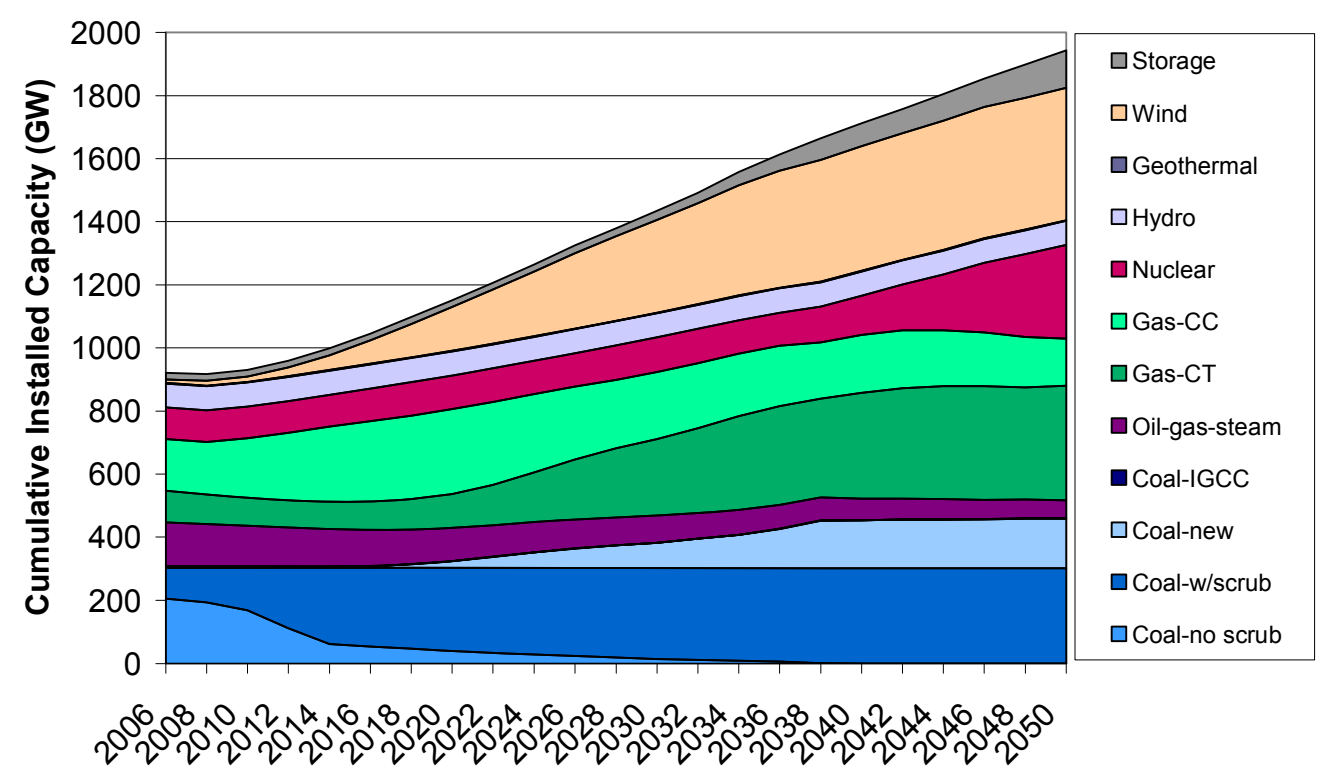

Figure 9. Cumulative installed capacity, $20 \%$ wind by 2030 with storage case

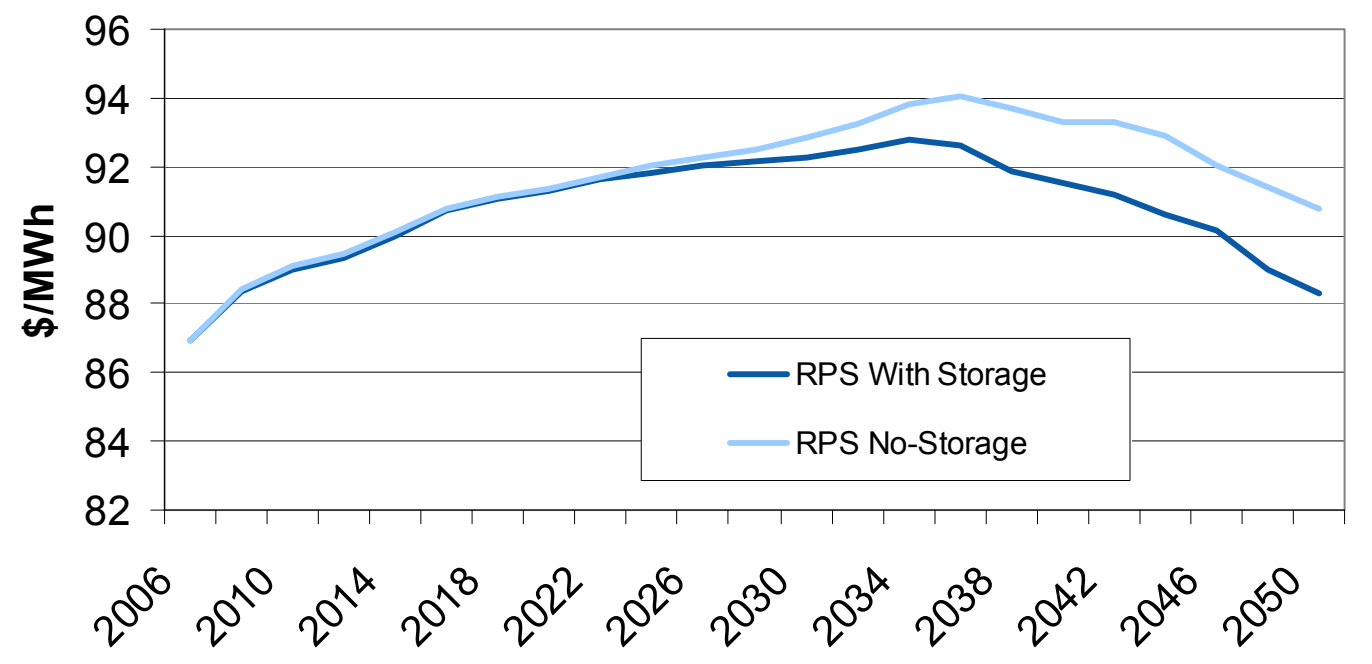

Figure 10. Electricity price comparison, $20 \%$ wind by 2030 case 
Figure 11 contains a pair of graphs showing the build-out of storage capacity and changes in generation from storage in the $20 \%$ wind case. The charts begin in 2006 with the $21 \mathrm{GW}$ of existing capacity and $26 \mathrm{TWh}$ of storage - a number that closely matches actual output from storage in 2006. Generation decreases after 2006 as the generating mix includes more natural gas. Gas is a more flexible technology than coal and neither requires backup nor benefits much from load shifting, so storage becomes less desirable in those years. As wind is built and natural gas becomes more expensive, however, generation from storage recovers and then surpasses the 2006 value. By 2024, storage has become sufficiently valuable that building additional storage capacity becomes viable. From then on, storage grows rapidly —in both capacity and generation.

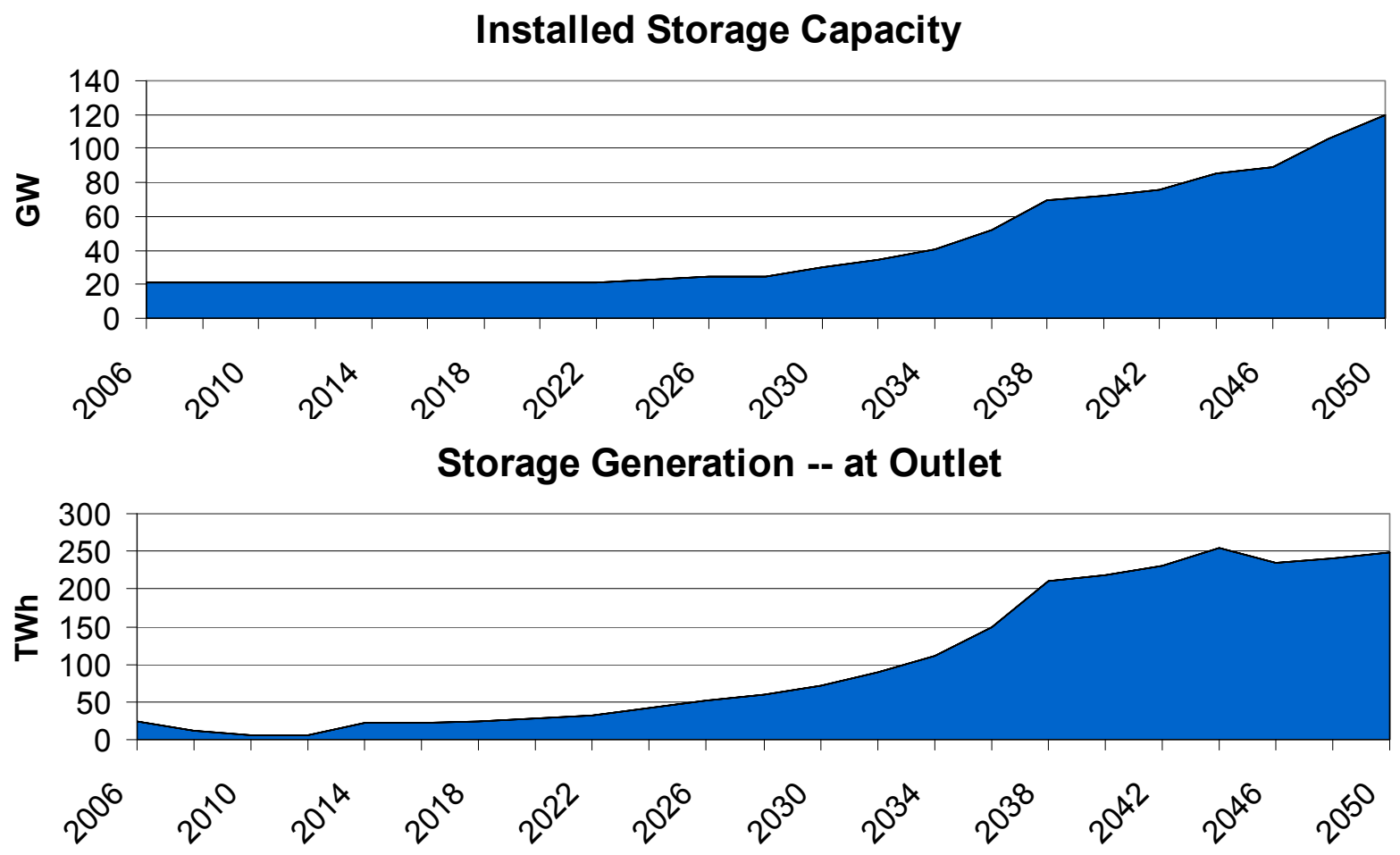

Figure 11. Storage build-out, $20 \%$ wind by 2030 with-storage case

More storage capacity is built in the $20 \%$ case than in the business-as-usual case: 120 $\mathrm{GW}$ by 2050, compared to $97 \mathrm{GW}$. Furthermore, just as more wind capacity is built earlier in the $20 \%$ case, there are $70 \mathrm{GW}$ of storage installed by 2038 in the $20 \%$ case, while only $28 \mathrm{GW}$ are installed by that time in the business-as-usual case (see Figure 12). That more wind leads to more storage is further indication that storage is providing tangible benefit to wind specifically, not just to the grid as a whole. Nevertheless, it is also the case that even in this aggressive scenario, the model did not build new storage until 2024, when there were already $200 \mathrm{GW}$ of wind capacity on the grid supplying $15 \%$ of the nation's energy. 


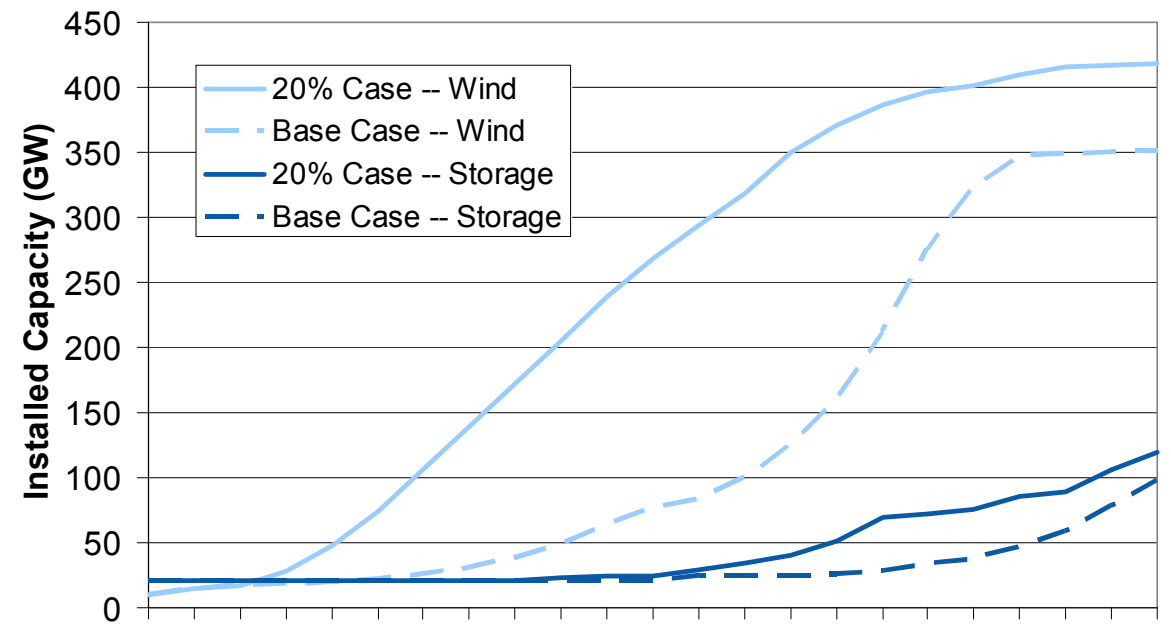

200620102014201820222026203020342038204220462050

Figure 12. Storage and wind growth comparison

\section{Diurnal Behavior of Storage in ReEDS}

The charging and discharging cycles of storage units are of tangential interest to this study. While they may not directly demonstrate benefits of storage to wind, they do show how storage interacts with the system and add legitimacy to the study's conclusions, showing predictable and explainable behavior.

Figure 13 is a chart of power output - national total in 2030 , in the $20 \%$ wind case - of each major generator type by time-slice. As expected, base-load technologies such as nuclear and coal change little from hour-to-hour or day-to-day. Natural gas plants are used to meet higher daytime loads, with single-cycle plants coming online only after the combined-cycle plants are already dispatched. Storage charges during overnight hours, when coal is on the margin, and discharges during the peak period each day, replacing gas generation. 


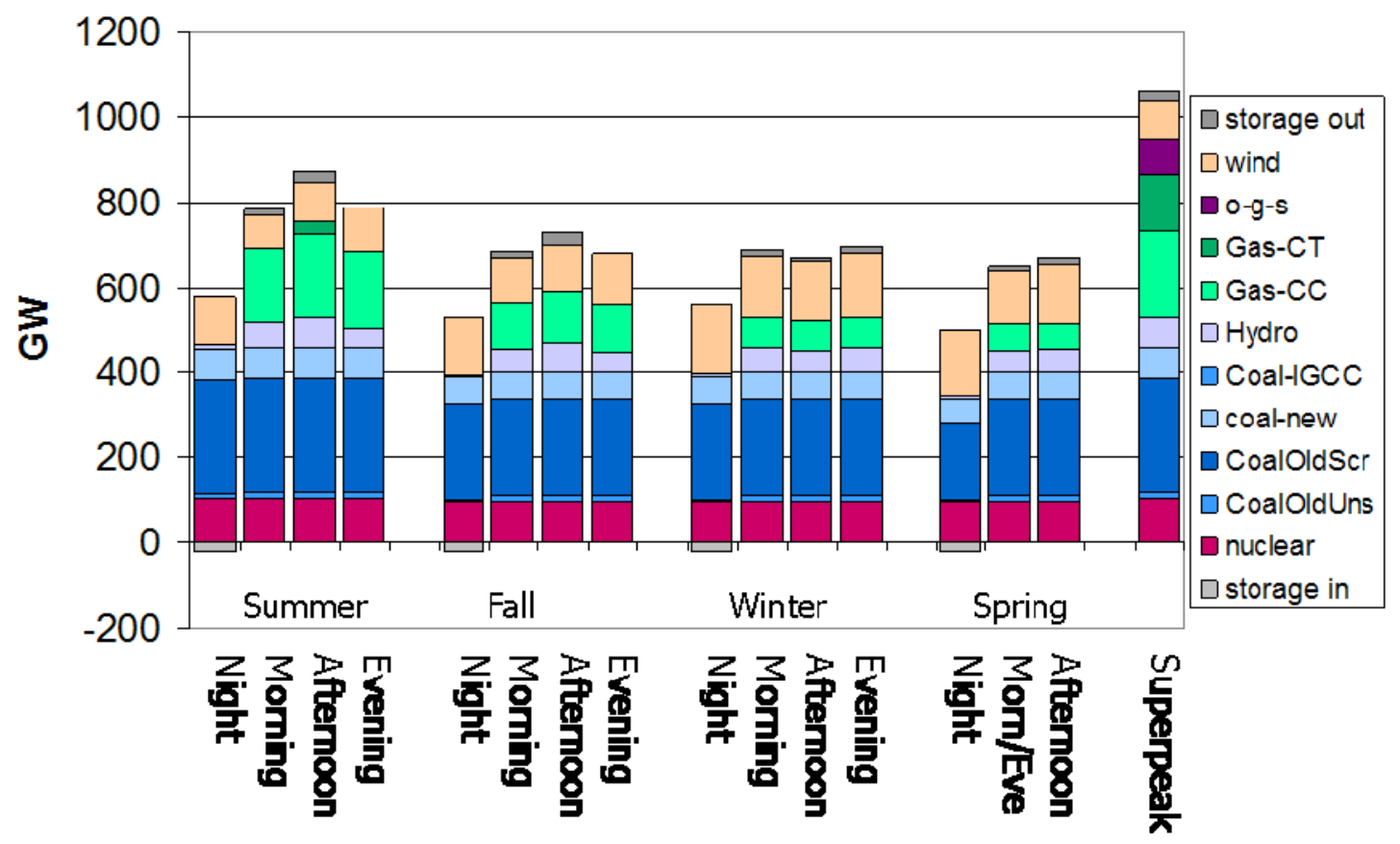

Figure 13. Generation by time slice (2030)

Figure 14 is similar, but contains only storage; and the width of each time-slice is proportional to the number of annual hours in that time-slice (e.g. winter occupies four months to fall's two). In this chart, it is apparent that stored energy may not be transferred from one season to another: for each season, energy-in matches the energy-out once round-trip efficiency is considered. Also, the diurnal trend of charging overnight and discharging during the day is evident.

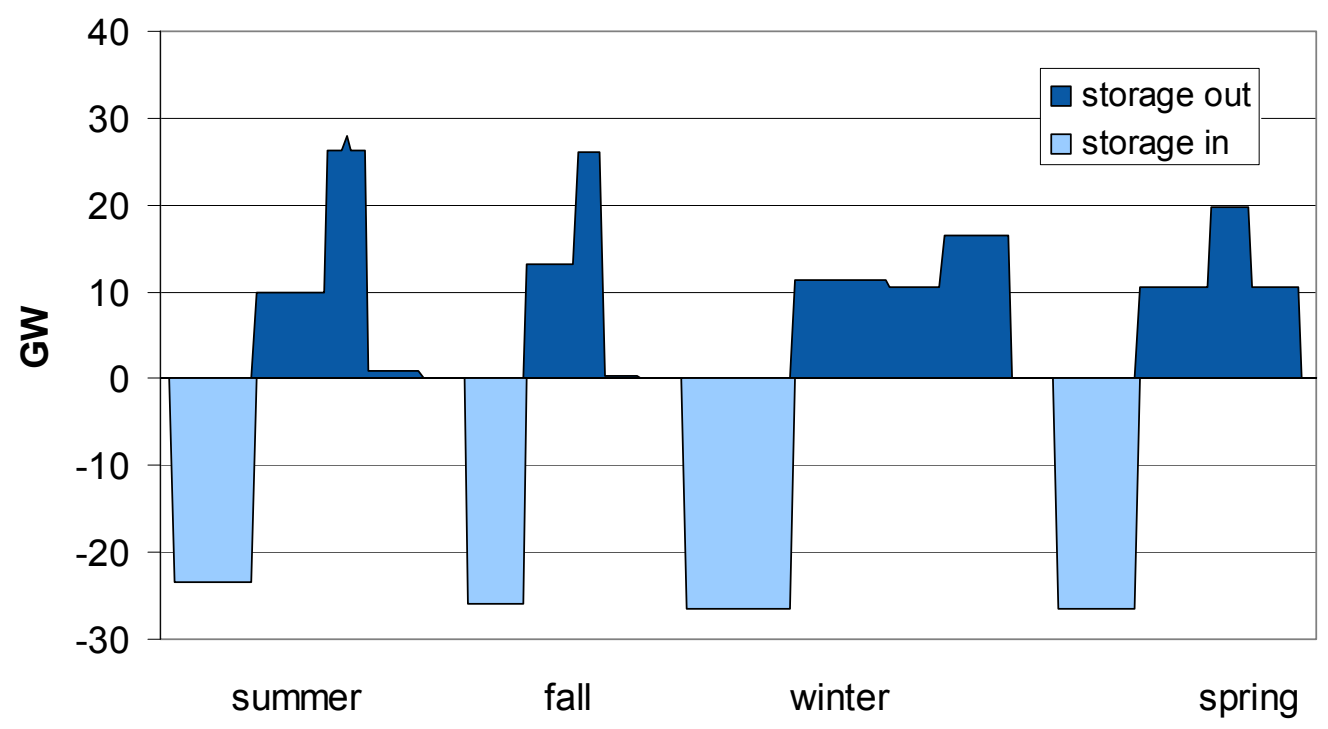

Figure 14. Hourly storage profile (2030) 


\section{Summary and Conclusions}

Several types of storage, including CAES, PHS, and batteries, have been added to the ReEDS model. Under several scenarios, results from this new capability have proved to be realistic and explainable. The new capability was used for this analysis but will now become a standard component of the larger ReEDS model. The results presented here demonstrate that at high levels of penetration storage can lead to more wind power installations. Within the constraints of the ReEDS model and with the assumptions outlined above, this analysis showed that CAES plants can be economically competitive with conventional technologies in the future and that the ability to store electricity adds value to the system as a whole and to wind power in particular.

In the business-as-usual cases, the capability to build and use storage allowed an increase in 2050 wind capacity from $302 \mathrm{GW}$ in the no-storage case to $351 \mathrm{GW}$ in the storage case. The scenarios were otherwise identical, so the additional capacity, which was not economically competitive with conventional sources in the no-storage case, must have become competitive in the storage case. Comparisons also show that the additional wind and storage have replaced both capacity and generation from conventional sources.

In the $20 \%$ wind by 2030 cases, the results show that with a fixed amount of wind generation, storage can lower electricity prices, a good proxy for the cost of the overall system. For both the business-as-usual cases and the $20 \%$ wind cases, results indicate that the value of storage to wind increases along with amount of wind in the system. However, storage does not become sufficiently valuable to warrant the investment until there is significant wind capacity already on the grid.

Analysis of the charge-discharge behavior of storage with the seasonal and diurnal behavior of the system as a whole indicates that storage is behaving in ways that are consistent and explainable, lending credence to the other results. 


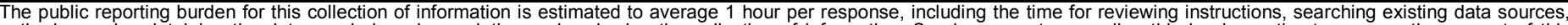

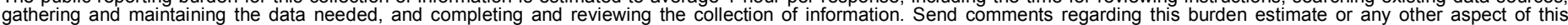



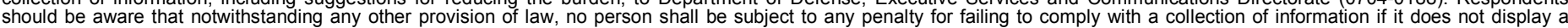

chorrd be alid OMB control number.

PLEASE DO NOT RETURN YOUR FORM TO THE ABOVE ORGANIZATION.

\begin{tabular}{|l|l|l|l} 
1. REPORT DATE (DD-MM-YYYY) & 2. & REPORT TYPE & 3. DATES COVERED (FrOm - TO)
\end{tabular} June 2008

Conference paper

4. TITLE AND SUBTITLE
Modeling the Benefits of Storage Technologies to Wind Power

5a. CONTRACT NUMBER

DE-AC36-99-GO10337

5b. GRANT NUMBER

5c. PROGRAM ELEMENT NUMBER

6. AUTHOR(S)

P. Sullivan, W. Short, and N. Blair

5d. PROJECT NUMBER

NREL/CP-670-43510

5e. TASK NUMBER

0664.0701

5f. WORK UNIT NUMBER
7. PERFORMING ORGANIZATION NAME(S) AND ADDRESS(ES)

National Renewable Energy Laboratory

1617 Cole Blvd.

Golden, CO 80401-3393

9. SPONSORING/MONITORING AGENCY NAME(S) AND ADDRESS(ES)
8. PERFORMING ORGANIZATION REPORT NUMBER

NREL/CP-670-43510

10. SPONSOR/MONITOR'S ACRONYM(S) NREL

11. SPONSORING/MONITORING AGENCY REPORT NUMBER

12. DISTRIBUTION AVAILABILITY STATEMENT

National Technical Information Service

U.S. Department of Commerce

5285 Port Royal Road

Springfield, VA 22161

13. SUPPLEMENTARY NOTES

\section{ABSTRACT (Maximum 200 Words)}

Rapid expansion of wind power in the electricity sector is raising questions about how wind resource variability might affect the capacity value of wind farms at high levels of penetration. Electricity storage, with the capability to shift wind energy from periods of low demand to peak times and to smooth fluctuations in output, may have a role in bolstering the value of wind power at levels of penetration envisioned by a new Department of Energy report ("20\% Wind by 2030, Increasing Wind Energy's Contribution to U.S. Electricity Supply"). This paper quantifies the value storage can add to wind. The analysis was done employing the Regional Energy Deployment System (ReEDS) model, formerly known as the Wind Deployment System (WinDS) model. ReEDS was used to estimate the cost and development path associated with $20 \%$ penetration of wind in the report. ReEDS differs from the WinDS model primarily in that the model has been modified to include the capability to build and use three storage technologies: pumped-hydroelectric storage (PHS), compressed-air energy storage (CAES), and batteries. To assess the value of these storage technologies, two pairs of scenarios were run: business-as-usual, with and without storage; $20 \%$ wind energy by 2030 , with and without storage. This paper presents the results from those model runs.

\section{SUBJECT TERMS}

NREL; wind energy; $20 \%$ by 2030; storage; Wind Deployment System model; WinDS; Regional Energy Deployment System model; ReEDS; pumped-hydroelectric storage; compressed-air energy storage; Nate Blair; Walter Short; Patrick Sullivan

\section{SECURITY CLASSIFICATION OF:}

\begin{tabular}{l|l|l|}
\hline a. REPORT & b. ABSTRACT & c. THIS PAGE
\end{tabular}

Unclassified Unclassified Unclassified

\begin{tabular}{|c|c|}
\hline $\begin{array}{l}\text { 17. LIMITATION } \\
\text { OF ABSTRACT }\end{array}$ & $\begin{array}{ll}\text { 18. } & \text { NUMBER } \\
\text { OF PAGES }\end{array}$ \\
\hline UL & \\
\hline
\end{tabular}

19a. NAME OF RESPONSIBLE PERSON

19b. TELEPHONE NUMBER (Include area code) 